\title{
Bilateral Internal Thoracic Artery Minimally Invasive CABG Management in COPD
}

\author{
Anna Kathrin Assmann ${ }^{1}$ Artur Lichtenberg ${ }^{1} \quad$ Alexander Assmann ${ }^{1}$ \\ ${ }^{1}$ Department of Cardiac Surgery, Heinrich Heine University, Medical \\ Faculty, Duesseldorf, Nordrhein-Westfalen, Germany \\ Thorac Cardiovasc Surg Rep 2022;11:e14-e16.

\begin{abstract}
Address for correspondence Prof. Dr. med. Alexander Assmann, MHBA, Department of Cardiac Surgery, Heinrich Heine University, Moorenstraße 5, Duesseldorf 40225, Germany
\end{abstract} \\ (e-mail: alexander.assmann@med.uni-duesseldorf.de).
}

\author{
Abstract \\ Keywords \\ - coronary artery \\ bypass grafting \\ - off-pump CABG \\ - LITA \\ - RITA \\ - minimally invasive \\ cardiac surgery \\ (MICS) \\ - chronic obstructive \\ pulmonary disease \\ (COPD)
}

Background Off-pump multi-arterial minimally invasive coronary surgery via anterolateral mini-thoracotomy has become a feasible and safe procedure.

Case Description We report on a 61-year-old patient with a coronary one-vessel disease with severely stenotic left anterior descending artery and diagonal branch, additionally suffering from chronic obstructive pulmonary disease with severely impaired lung function. Using a fan technique allowing for double lung ventilation, the patient was successfully operated grafting both internal thoracic arteries via a left anterolateral mini-thoracotomy.

Conclusion Anaortic, minimally invasive off-pump coronary artery bypass grafting is an excellent technique to achieve myocardial revascularization with both internal thoracic arteries even in patients with impaired lung function.

\section{Introduction}

Over the last decade, coronary artery bypass grafting (CABG) has evolved toward innovative minimally invasive approaches (minimally invasive cardiac surgery-coronary artery bypass grafting [MICS-CABG]), that have been described to be as safe as sternotomy-based off-pump CABG (OPCAB) but exhibit less wound infection, better cosmetic outcome, more rapid postoperative recovery, and shorter in-hospital stay compared with conventional OPCAB. ${ }^{1}$ Continuous technological optimization has made off-pump MICS-CABG an excellent and safe alternative for complete myocardial revascularization, so far particularly for younger patients with low comorbidity profile.

\section{Case Description}

We report on a 61-year-old patient suffering from coronary one-vessel disease with a severely stenotic left anterior descending artery and a severely stenotic diagonal branch in an intermediate branch position ( $\mathbf{- F i g . ~ 1 ) . ~ A d d i t i o n a l l y , ~}$ the patient with a 45-year history of daily smoking showed a chronic obstructive pulmonary disease with severely impaired lung function exhibiting a combination of restriction and obstruction under inhalative triple therapy combining beclometasone, formoterol, and glycopyrronium (forced expiratory volume in one second $1.6 \mathrm{~L}$ [48\%], vital capacity $2.2 \mathrm{~L}$ [51\%], peak expiratory flow $3.5 \mathrm{~L} / \mathrm{s}$ [41\%], mean expiratory flow at $75 \%$ of forced vital capacity (MEF-75) $2.3 \mathrm{~L} / \mathrm{s}$ [31\%], MEF-50 1.3 L/s [29\%], and MEF-25 0.7 L/s [38\%]).

The patient underwent off-pump MICS-CABG via left anterolateral mini-thoracotomy (-Fig. 2A). To achieve double lung ventilation, our previously described fan technique was applied. ${ }^{2}$ In short, the pericardium was incised preserving the phrenic nerve, and traction sutures (8-12) were stitched along the pericardiopleural margin. All sutures were collected and pulled through the third intercostal space received

June 27, 2021

accepted

July 20, 2021
DOI https://doi.org/ 10.1055/s-0041-1739186. ISSN 2194-7635.

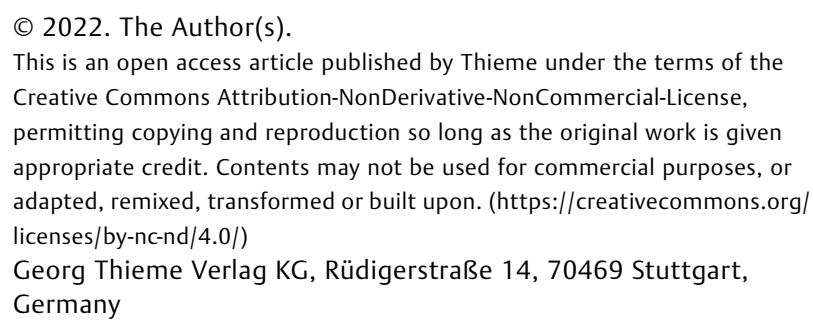




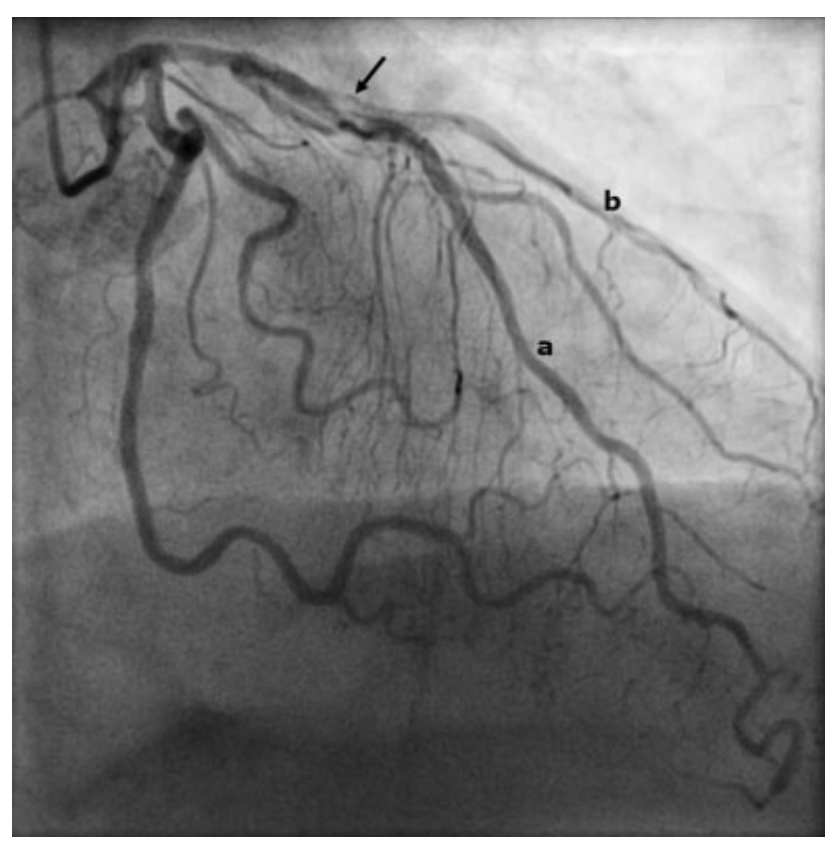

Fig. 1 Preoperative coronary angiogram showing a severely stenotic left anterior descending artery (a) and a severely stenotic diagonal branch in an intermediate branch position (b). $\rightarrow$, stenoses.

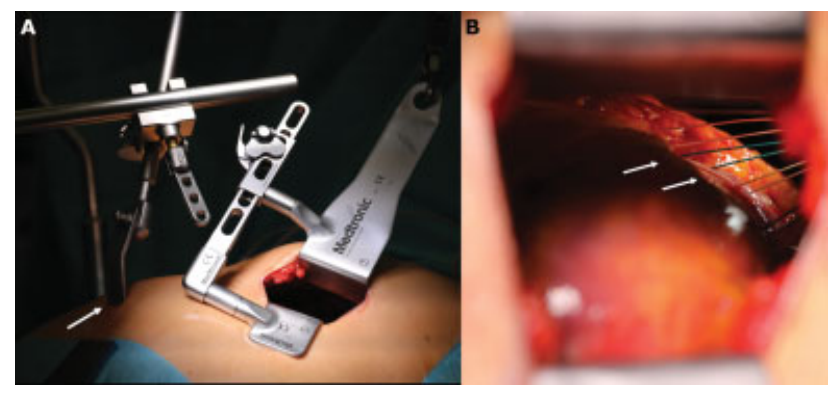

Fig. 2 (A) Surgical access via a left anterolateral mini-thoracotomy using a lifting retractor for LITA (left internal thoracic artery) harvesting and an additional sub-xiphoidal retractor $(\rightarrow$ ) for RITA (right internal thoracic artery) harvesting. (B) Installation of the fan $(\rightarrow)$ to retract the left lung allowing for continuous double lung ventilation.

close to the midaxillary line, so that a fan was created that retracted the left lung allowing for double lung ventilation (-Fig. 2B).

First, the left internal thoracic artery (LITA) was prepared following a skeletonization approach. By means of the additionally placed sub-xiphoidal retractor to lift the sternum (-Fig. 2A), the right internal thoracic artery (RITA) was also skeletonized (-Fig. 3A). Both lungs exhibited severe anthracosis.

After calculation of the bypass architecture, the RITA graft was proximally anastomosed to the LITA in a T-graft geometry using a stabilization platform (-Fig. 3B). Afterward, the peripheral coronary target anastomoses were constructed, suturing the LITA to the left ascending artery and the RITA to the significant first diagonal branch ( $\mathbf{F i g}$. $3 \mathbf{C}$ ). Transit time flow measurement after release of bypass perfusion was conducted showing excellent blood flow to both coronary targets.
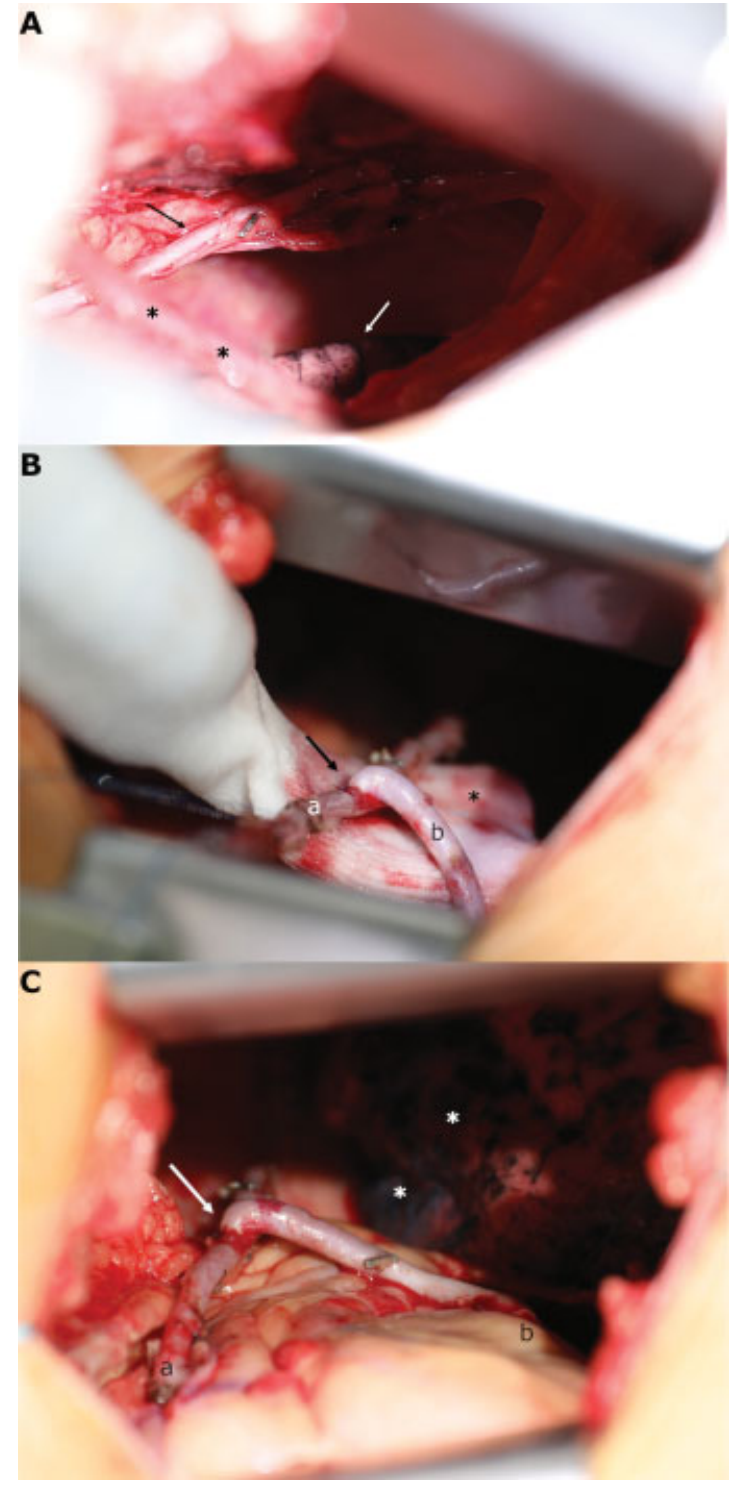

Fig. 3 (A) Preparation of the internal thoracic arteries. black $\rightarrow$, RITA (right internal thoracic artery); ${ }^{*}$, LITA (left internal thoracic artery), white $\rightarrow$, pulmonary anthracosis. (B) Proximal anastomosis of the LITA (left internal thoracic artery) (a) and the RITA (right internal thoracic artery) (b) with T-graft configuration $(\rightarrow$ ) on the stabilization platform $\left(^{*}\right)$. (C) Final bypass graft configuration. $\rightarrow$, T-graft; a, LITA (left internal thoracic artery); b, RITA (right internal thoracic artery); *, severe pulmonary anthracosis.

During the whole operation, a double lung ventilation could be achieved, resulting in adequate oxygenation and carbon dioxide removal.

Postoperatively, the patient was transferred to the intensive care unit and could be extubated 2 hours later. The patient was further transferred to the normal ward on the second postoperative day and was discharged from the hospital on the sixth postoperative day.

\section{Discussion}

Off-pump multivessel MICS-CABG via an anterolateral minithoracotomy has become a feasible and safe procedure. ${ }^{3,4}$ The ability to visualize and access both internal thoracic 
arteries, supported by an additionally placed sub-xiphoidal retractor if required, enables for total arterial revascularization of almost all myocardial territories.

Multiple studies and meta-analyses have supported the superiority in patency of arterial grafts compared with venous grafts. ${ }^{5-7}$ Furthermore, the use of both internal thoracic arteries allows for surgery without aortic manipulation (anaortic technique) in the majority of patients. As previously described, anaortic coronary surgery significantly reduces the incidence of intraoperative stroke. ${ }^{8}$

In patients with severely impaired lung function, the use of our previously described fan technique allows for double lung ventilation without impairing the surgeon's view and space, while supporting adequate gas exchange. ${ }^{2}$

Compared with conventional OPCAB via sternotomy, offpump MICS-CABG enables faster recovery after surgery, less wound infections, and reduced in-hospital stay. ${ }^{1}$

In conclusion, anaortic off-pump MICS-CABG is an excellent technique to achieve myocardial revascularization with both internal thoracic arteries even in patients with impaired lung function. This approach expands the modular spectrum of innovative coronary surgery which aims at individualized therapy not at last for multimorbid patients.

\section{Authors' Contributions}

A.K.A. contributed toward drafting the manuscript and visualization. A.L. did the review, editing, and collected the resources. A.A. contributed toward the conception of work, performed the operation, and critical revision of the article.
Conflict of Interest

None declared.

\section{References}

1 Lapierre H, Chan V, Sohmer B, Mesana TG, Ruel M. Minimally invasive coronary artery bypass grafting via a small thoracotomy versus off-pump: a case-matched study. Eur J Cardiothorac Surg 2011;40(04):804-810

2 Albert A, Assmann A, Assmann AK, Aubin H, Lichtenberg A. Operative Techniques in Coronary Artery Bypass Surgery-An Illustrated Guide to Personalized Therapy. London: Springer International Publishing; 2021:54-55

3 Gaudino M, Bakaeen F, Davierwala P, et al. New strategies for surgical myocardial revascularization. Circulation 2018;138(19): 2160-2168

4 Davierwala PM, Verevkin A, Sgouropoulou S, et al. Minimally invasive coronary bypass surgery with bilateral internal thoracic arteries: Early outcomes and angiographic patency. J Thorac Cardiovasc Surg 2021 Oct;162(4):1109-1119.e4. doi: 10.1016/j. jtcvs.2019.12.136. Epub 2020 Apr 8

5 Benedetto U, Raja SG, Albanese A, Amrani M, Biondi-Zoccai G, Frati G. Searching for the second best graft for coronary artery bypass surgery: a network meta-analysis of randomized controlled trials. Eur J Cardiothorac Surg 2015;47(01):59-65, discussion 65

6 Buttar SN, Yan TD, Taggart DP, Tian DH. Long-term and short-term outcomes of using bilateral internal mammary artery grafting versus left internal mammary artery grafting: a meta-analysis. Heart 2017;103(18):1419-1426

7 Taggart DP, Altman DG, Gray AM, et al.ART Investigators. Randomized trial of bilateral versus single internal-thoracic-artery grafts. N Engl J Med 2016;375(26):2540-2549

8 Albert A, Ennker J, Hegazy Y, et al. Implementation of the aortic no-touch technique to reduce stroke after off-pump coronary surgery. J Thorac Cardiovasc Surg 2018;156(02):544-554.e4 